\title{
Consumer Saving Rises
}

F 1 CONOMIC ACTIVITY has been accelerating since the spring of last year, but increases in consumer expenditures have been moderate relative to the growth of income. Households have been saving a relatively large portion of their after-tax income. Although such behavior is not uncommon for short periods of time, the maintenance of such a patterm over a period of a year and a half has been unexpected by some analysts.

The higher saving rate has caused much comment in the financial press. Some view it with great concern as a potential weakness in the economy; others view it as a pool of potential excessive demand. Various explanations for a temporary increase in the saving rate have been offered. This note takes the view that recent consumer behavior was neither random nor serious, but reflected rational consumer response to economic developments.

The shift to a higher rate of saving in late 1966 was

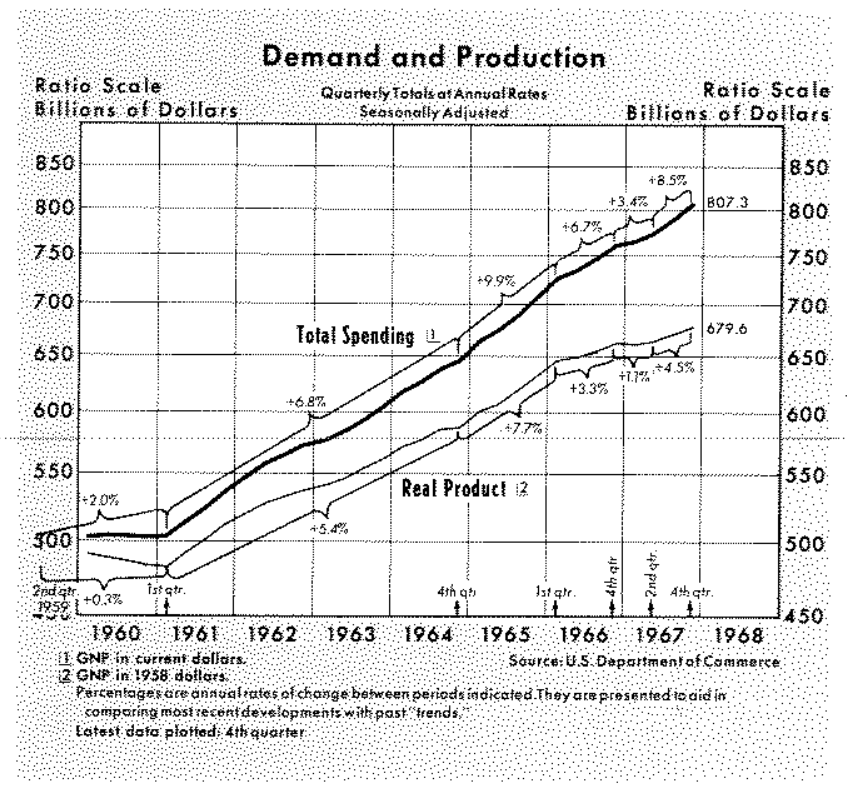

an important factor underlying the moderation of economic activity early in 1967, and was a desirable depressant later in the year when other forces became ebullient. The performance of the economy in 1968 depends in large part on whether consumers continue to save a relatively large portion of their income or increase their demands for goods and services.

\section{Sachering}

Total spending has increased at a 9 per cent annual rate since the second quarter of 1967 , with investment demand accelerating especially rapidly. Investment spending, which had declined sharply in the first half of the year, mainly due to a drastic reduction in inventory investment, expanded significantly in the second half. Most of the rebound in investment spending was due to inventory accumulation, which rose from an annual rate of $\$ 0.5$ billion in the second quarter to $\$ 9$ billion in the fourth quarter. Residential construc-

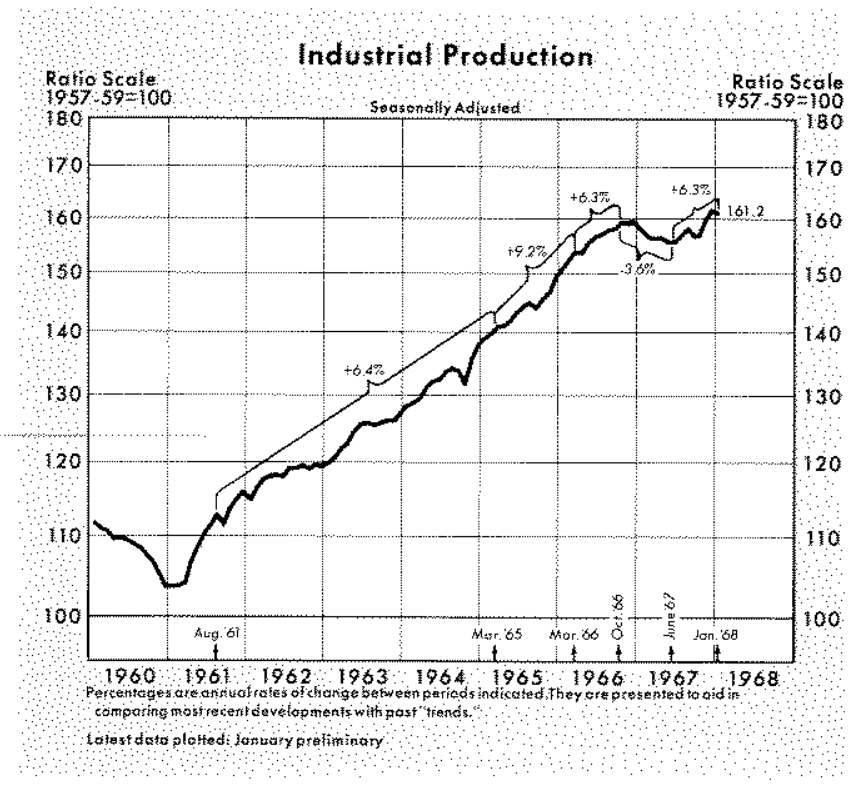




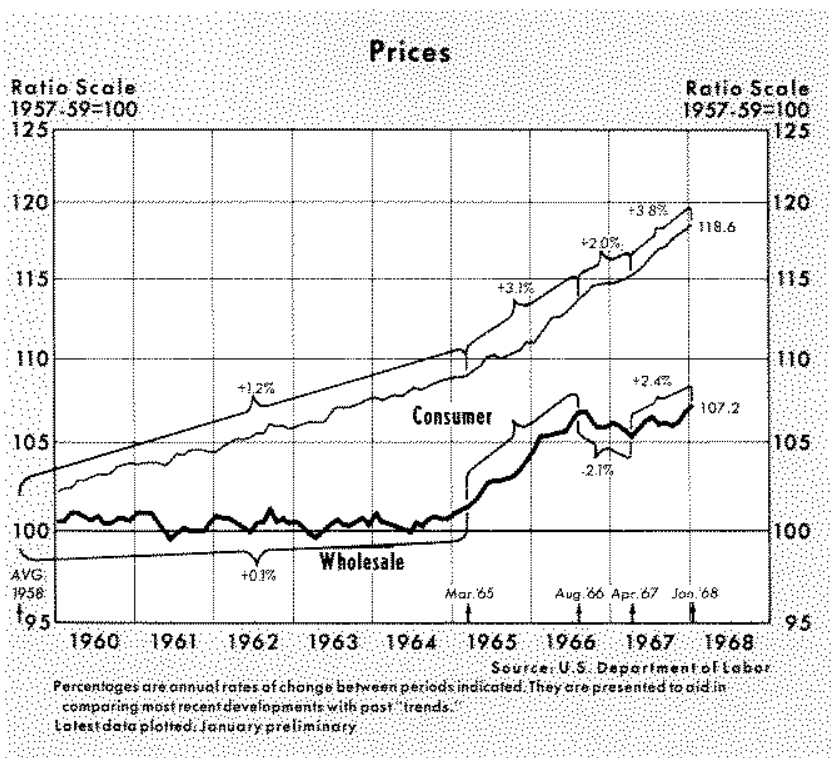

tion rose throughout the year, after declining sharply in 1966. Investment in plant and equipment contributed little to the acceleration but shows promise of improvement in 1968, according to government surveys.

Employment and income have expanded since last spring, reflecting increased production. From June to January industrial output rose at a 6.3 per cent rate, following a period of decline over the previous ten months. Employment rose at a 3.3 per cent rate from last spring to January, compared with an estimated 2 per cent rate of expansion in the population of working-force age. Unemployment stood at 3.5 per cent of the labor force in January, the lowest rate since 1953. Personal income increased at an 8 per cent annual

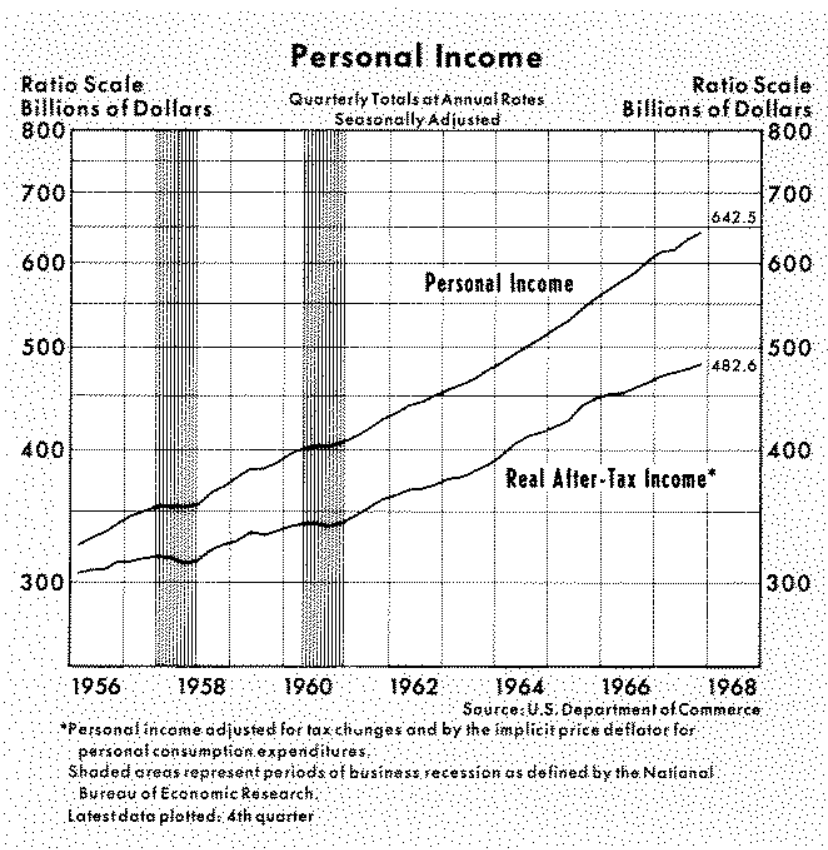

rate from last spring to January. From 1957 to 1967 income grew at a 6 per cent average rate.

Prices paid by consumers for commodities other than food have increased at a 4.5 per cent rate since July, after rising at a 2.2 per cent rate from December 1966 to July. Wholesale prices of industrial commodities increased at a 3.2 per cent rate from July to December and even more sharply in January and February.

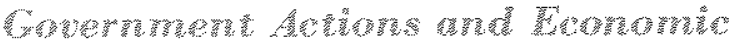

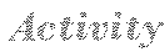

Government actions were a stimulative force in the economy in 1967. Reserves of member banks increased 10 per cent from January 1967 to last January, compared with a 4 per cent trend rate from 1960 to 1966.

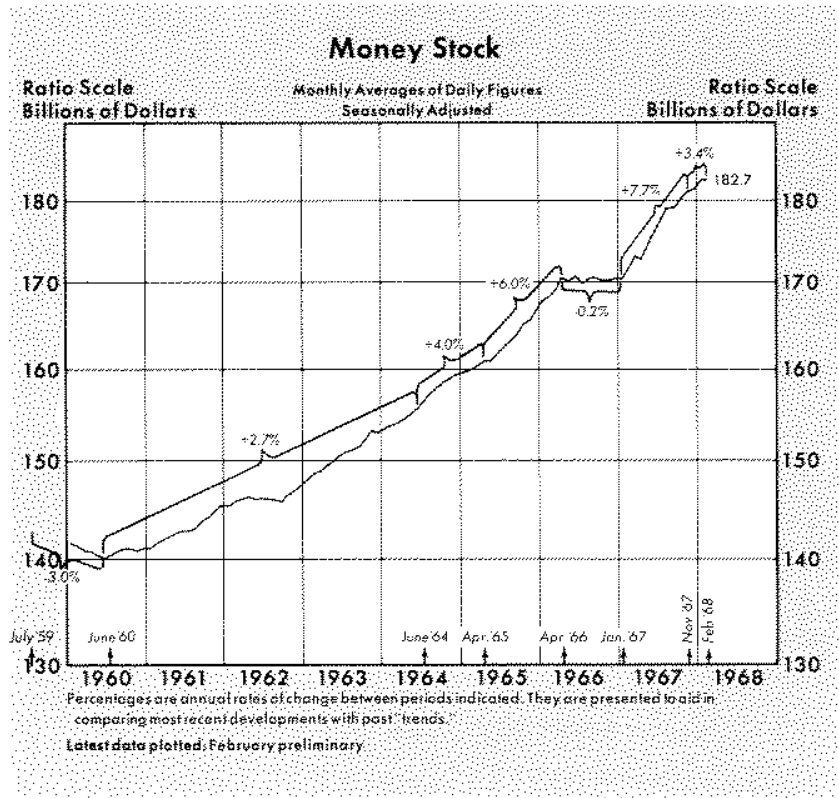

The money stock, currency plus demand deposits, increased 7.3 per cent in the year ending in January, a sharp acceleration from the previous nine months when the money stock changed little.

The expansionary force of fiscal actions moderated slightly late in 1967 but still remained much stronger than in 1966. The high-employment budget deficit was $\$ 11$ billion in the second half of 1967 , about unchanged from the first half but up sharply from a $\$ 3.4$ billion deficit in the second half of 1966. In the absence of the proposed tax surcharge, the stimulative force of fiscal actions would continue into 1968.

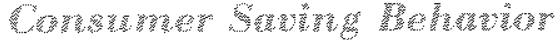

Despite acceleration of personal income, growth in consumer spending was moderate in the second half 
of last year. Since mid-1967 consumer spending has increased at a 5 per cent annual rate, compared with a 7 per cent rate of increase in the first half of the year. On balance, demand for goods, both durable and nondurable, has moderated since mid-year. The slowdown in consumer spending reflects an increased demand for financial assets relative to real goods. This was not a random event but resulted from the interaction of several conditions.

Individuals buy real goods and financial assets for the services or satisfaction which can be derived from their use. Since the amount they can acquire is limited by income and the ability to obtain credit, individuals are forced to make decisions; some wants must be sacrificed in order to achieve others. They seek to acquire that combination of items which provides maximum satisfaction. These decisions are made by comparing benefits and costs, and that combination of real goods and financial assets is chosen which provides maximum possible satisfaction, given income and the availability and cost of credit.

The recent allocation of an increased share of income to financial assets has reflected the increasing costs of real goods and the expansion of the benefits offered by financial assets. On balance, the prices of real goods have risen at an accelerated rate since early in 1966. In addition, the high and rising nature of inter-

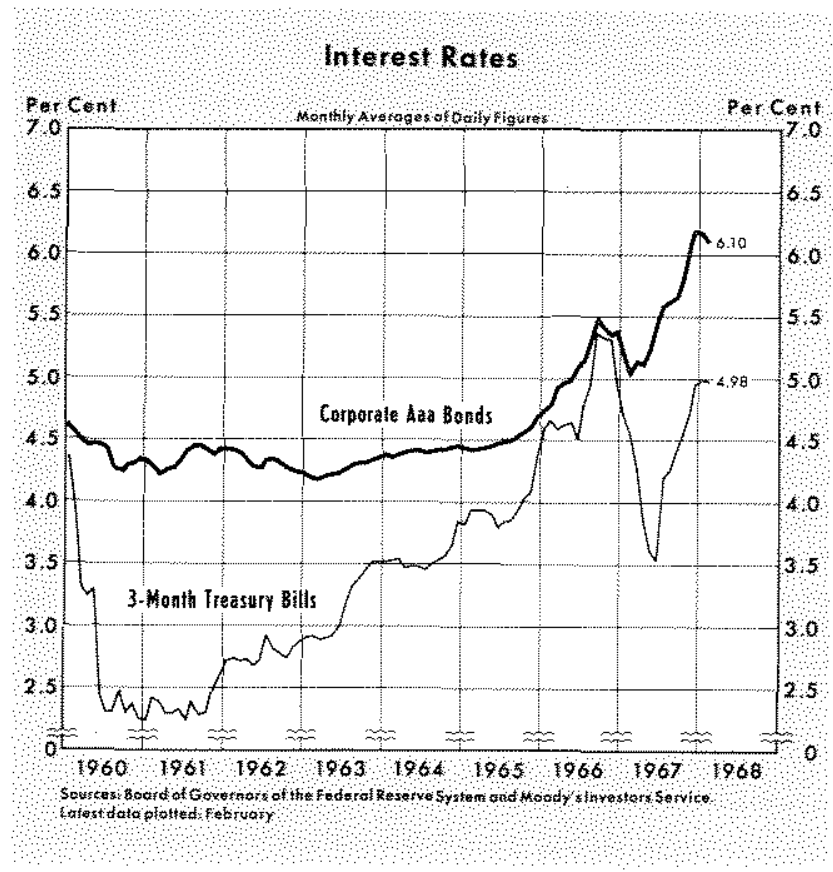

est rates over the period not only increased the cost of constmer credit but also the return on financial assets. While price increases and interest rates moderated late in early 1967, individuals did not significantly reduce the portion of total income allocated to financial assets. Instead, they merely moved a portion of their assets from interest-bearing instruments to currency and demand and time deposits in an attempt to build liquidity which had been lost earlier. Since mid-1967 prices have accelerated, and interest rates have again moved upward. Individuals have responded by moderating the growth of consumer spending and diverting an increased share of after-tax income (from 6.7 per cent in the second quarter of 1967 to 7.5 per cent in the fourth quarter) to financial assets.

In addition to high interest return, financial assets are providing other services to individuals. The rising cost of such items as education and medical care has resulted in increasing the amount of funds which must be set aside for future use. The threat of a tax increase has probably caused some individuals to sacrifice present consumption of real goods in order to meet expected higher tax liabilities. Uncertainty about future developments in Asia has been another factor in inducing consumers to save their purchasing power. A partial offset might be expectations of continued inflation, which would tend to induce consumers to buy real goods at present prices.

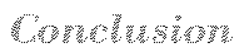

The increased share of income allocated to savings reflects the response of individuals to the acceleration of prices and rising interest rates. Pressure on prices and interest rates has in large part been due to stabili- 


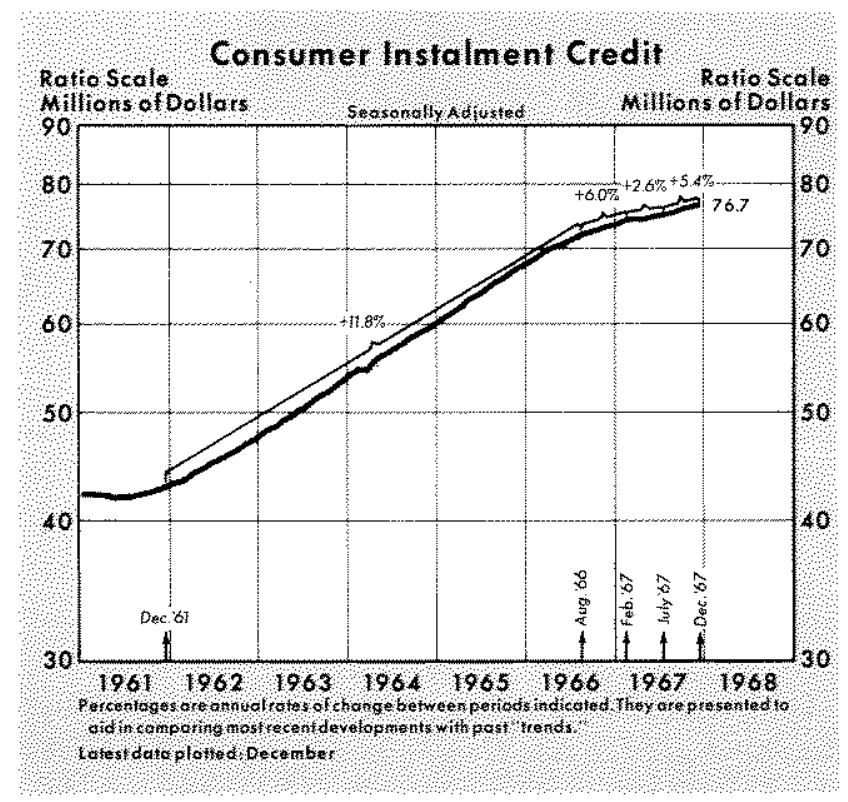

zation policies pursued since 1966. Strong demand for goods and services by the government sector contributed to the rapid increases in prices, and the large budget deficits put upward pressure on interest rates. Rapid monetary expansion late in 1967 was an expansionary force, stimulating private demand for goods and services and adding to pressure on prices and interest rates.

Given the growth of Government spending for war and welfare programs, and given the increase of business spending resulting from stimulative fiscal and monetary actions, there was only a limited amount of productive resources left to satisfy consumers. Consumers were, in effect, rationed goods and services by a combination of higher interest rates and higher prices. Their behavior was entirely consistent with the conditions existing, and there is no reason to bem lieve that individuals have made a long-run fundamental shift to a higher saving rate. There is little likelihood that consumers will change their saving rate without a significant change in underlying economic conditions.

Consumer behavior has operated as an automatic stabilizer in the economy. Expansionary fiscal and monetary actions in 1967 resulted in rapidly rising business and government expenditures. Consumers, in turn; increased their spending on goods and services at a slower rate but acquired more financial assets issued by the other sectors. 